\title{
Innovative Solution for Distance Education in a Developing Region
}

\author{
Jean Carlos Cavaleiro, Elisângela Mônaco de Moraes, \\ Reinaldo de Araújo Lopes, and Pedro Luiz de Oliveira Costa Neto \\ Paulista University-UNIP, Graduate Program in Production Engineering, \\ Dr. Bacelar St. 1212, São Paulo, Brazil \\ ajean@ig.com.br, politeleia@uol.com.br, \\ mestradoua@bol.com.br, emonaco@unip.br
}

\begin{abstract}
This work is about a project on distance education in a developing country, adapted to the needs of one of the poorest areas in Brazil. The difficulty due to the lack of access to broadband internet has made the government to contract a study for the development of a project to break the barrier of digital exclusion in that region. The article details the technique deployed to distribute materials on a large scale through digital medium, by which the students can develop activities and send them to teachers during attendance classes at study centers. The project is at implementation phase, but it is expected that it be useful also for other Brazilian States.
\end{abstract}

Keywords: Knowledge, Distance Education, Technological Restriction, Mobility.

\section{Introduction}

This paper describes one of the advances that the State of Piauí has had in recent years using the practicalities of Distance Education, with emphasis on an innovative solution developed to solve arising problems due to limitation, resulting from the unfeasibility of the use of broadband internet throughout the state and inaccessibility to computing equipment at homes. The State field of research has been for decades among those with the lowest HDI - Human Development Index in the country, with worse per-capita income and low investment in technology and infrastructure. This situation has been changing since 2007 as the State's GDP has grown above the national average, reaching in 2010, 22 billion Reais, and in 2012 reached 24 billion, according to IBGE [1]; amount that represents $0.5 \%$ of National GDP. Located in the northeast of Brazil, Piauí has Teresina as its capital city, with an estimated population of 836 thousand people in 2013. It is the third largest state in the region and the tenth of Brazil, with a land area of $251577 \mathrm{~km} 2$, corresponding to $2.9 \%$ of the national territory. Borders with five others Brazilian states: Maranhão, Ceará, Pernambuco, Bahia and Tocantins, as [2].

One of the features that put the state among the poorest in the country was the low qualification of labor, which, by the volume of students in rural areas, made it 
difficult the access to education. The Brazilian Institute of Geography and Statistics IBGE [2], states that the State of Piauí has a population of approximately 3 million people, with 1 million inhabiting the rural area and 2 million in the urban area. In 2010, exactly 829143 inhabitants were at school age, four to seventeen years old. Enrolled in high school, there were a total of 162027 inhabitants, of whom 140481 were students of public schools.

The low offer of regular high school courses occurs mainly by the lack of qualified professionals on most deprived regions and difficult of access in our country, one of them is the Rural Zone and the interior of Piauí. The geographical features and means of transportation available to residents of low density population communities form barriers for students to access the already existing high school.

The development then is conditional on growth of educational quality and the characteristics of the state were not conducive to that. Hence the difficulties require measures that make feasible the amenity to the student, independent of the type of access available to their city or community, thus respecting the express provision in the Federal Constitution, section II of Article 208, which guarantees as duty of the State "progressive universalization of free High School"and in Article 211, paragraphs 3 "the States and the Federal District shall act primarily in elementary and high school" and 4 "in the organization of their education systems, states and municipalities shall establish ways of collaboration in order to ensure the universalization of compulsory education".

To meet this challenge, the Government of Piaui, through the State Department of Education, conducts the implementation of High School Classes with Mediation of Technology, a project presented in APMS - 2013 [3], with the strong purpose of ensuring decent social conditions for these young people, offering them an education that enables the continuity of theirs studies, the construction and reconstruction of knowledge to the exercise of citizenship. The project has now, in 2014, the implementation of a new feature; the integration of virtual mobile learning environment, combined with a solution for distributing files on a large scale.

This project aims to reduce social exclusion, minimize the digital exclusion reducing school dropouts thus expanding the quality of labor available in the region.

\section{$2 \quad$ Methodology}

This work has the characteristics of a case study held in Piauí State, aiming to present an innovative solution in distance education due to the existence of a technological constraint. For this, the necessary references were searched and the descriptive method was used for the presentation of the results.

\section{DE - Distance Education}

The story relates the existence of distance education for many decades, in some secular situations, having as main definition, the education model where the student and teacher are not in the same environment or physical space at the same time, being 
mediated by technological resources with the assistance of teams prepared for interaction. The concepts are numerous, but follow the same direction, as you can see below the definitions of some authors.

Yarmohammadian et al. [4], in an article published in Science Direct, says that, distance education is a method in which the student is not physically present in educational environments and classrooms. A traditional concept, in keeping with the origins of distance education, where it sought to offer large scale knowledge independent of the distance between students and educational institution. Over time the definition below complete the one mention above.

For Shin et al. [ 5 ], distance education is a teaching model in which students can build knowledge anywhere and anytime, and for this it is enough to have learning objects, be mediated for integration to happen and consequently participate in an environment on which one can have an area of interaction.

This definition can now be considered a reflection of the evolution of information and communication technologies, where the construction and exchange of digital content, i.e. text, video or animations, becoming increasingly cheap and efficient.

Reinforcing this definition, Aretio [6] says that ICT - Information and Communication Technology has supported the main purpose of the distance education, which is decrease physical distance between teacher and student, and still provide competition on a Global level in the area of distance education. Hence the concerns in expanding investments in the area, for not suffer from already established models in the world.

Moore and Kearsley [7] states that, distance education is based on the planned learning that normally occurs in a different location from educational environments, which to the author requires special techniques of creation, organization and management, as well as communication through various technologiesDistance Education has expanded its importance to meet a suppressed demand for qualification of skilled labor, at various levels, free, professional, technical and upper level courses. Distance Education meets needs of countries with similar characteristics that of Brazil, where in some regions there is a lack of physical structures to meet the demands of education, lack of qualified teachers to work and where there are difficulties in locomotion, primarily in agricultural regions, and across the North and Northeast of the country. Consequently Distance Education has a role in social inclusion, bringing wide offer of quality education and flexibility demanded by the characteristics of the country.

\section{$4 \quad$ Project Description and Evaluation}

\subsection{The Antecedent}

As described above, the Distance Education is a teaching model that by the distance between student and teacher requires mediation by various technological resources, and aligned with the characteristics of each region and or groups involved. The Internet has been the basis of the proliferation of distance education in the world, but in Brazil the quality of broadband internet does not meet the needs of the online content transfer. Either by the capability or the costs involved, underserved regions such as 
the State of Piauí would not be able to make use of this modality in case internet use was essential to its development.

In the already mentioned [3], the authors presented the Project of Implementation of High School Classes with Technology Mediation in the State of Piaui, which constitutes the administrative-pedagogical alternative to attend graduating Elementary School students, from rural communities where there are no high school courses or the demand exceeds the number of places offered. The alternative was summed up in offering a High School course with differentiated and innovative methodology, with implementation of multimedia communication services (data, voice and image) and autonomy to cater the 224 municipalities in the eleven areas of development of the state; configuring a suppressed demand, thus aiming at social inclusion, taking quality education where there was none.

The model operates through a modern telecommunications platform, to offer the placement of modular curriculum series through video conferencing solution, including simultaneous access to Broadband Internet and allocation of multidisciplinary team to support pedagogical coordination in the implementation and operationalization of the project. The technologyconsist of Interactive Digital TV over IP via satellite VSAT (Very Small Aperture Terminal) platform.

The model presented demonstrated the project scope and reinforced its goal, which was to offer regular quality education to the general population, consequently facing the challenge of limited budgets for infrastructure, overcomes the shortage of schools and teachers. The figure 1 describes visually the model:

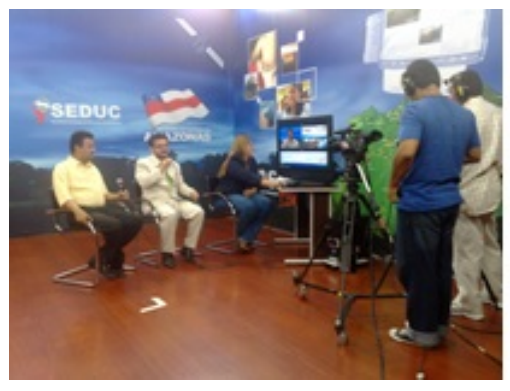

Fig. 1. (a) Ministering teachers

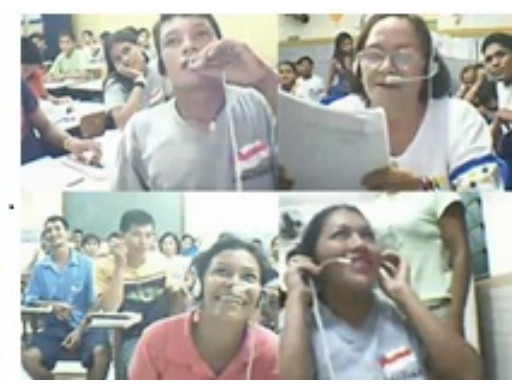

(b)Assistant teachers and students

In this model presented, ministrant teachers interact remotely with teaching assistants and students, interconnected via satellite by multipoint Interactive Digital TV over IP, with an appropriate and necessary interactivity as illustrated in Figure 2.

The continuity of the learning takes place through the development of activities at home, where students would access the lessons, solve the activities and would send through the platform to be corrected. This activity required that the students had some equipment in their homes, such as a computer with minimal configuration, broadband internet and domain on the use of these technologies. 


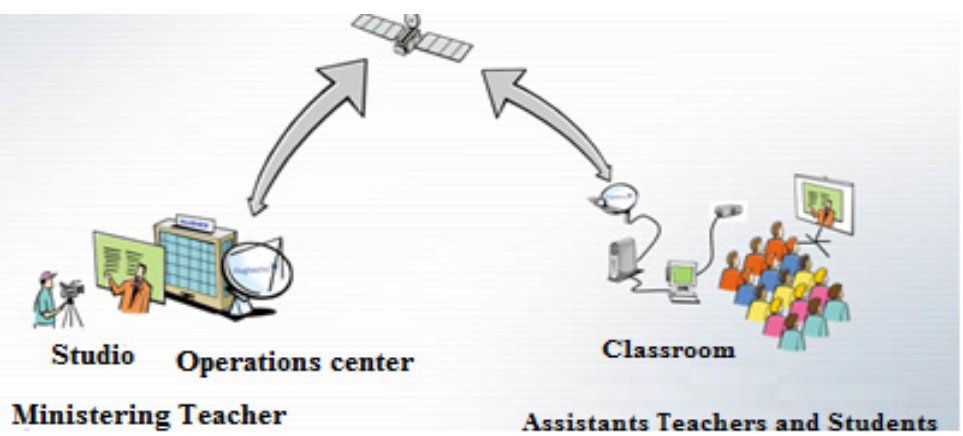

Fig. 2. Interaction between teacher and students

These necessities became barriers for the presented model to become even more promising than already was. From this difficulty emerged the second stage of the project, object of this article, which consists in a distribution solution of files in large scale combined with virtual mobile learning environment, more specifically with the use of tablets, associated to the structure available to the courses.

\subsection{Tablet Project}

The tablet project is a complement to the teaching model mediated by technology, proposed by the Government of the State of Piaui, consisting of a virtual mobile learning environment that will allow the student to access all courses content available on the tablets, even if it does not have internet connection. The student may attend classes, ask questions, contact teachers and do all exercises in offline mode. All data will be saved on the device. When going to the study center or outposts school for the mediated attended classes, students will have access to the wireless network (Wi-Fi), and on that moment, it can, not just download all data stored on the device, which will be sent to teachers, but still download new teaching materials for the next classes.

The project provides to the students of an educational institution in hand pedagogical content of all disciplines studied, gathered into a single mobile device, with a way to supplement regular classes or even a methodology for distance education courses that seeks to bring ways to expand the learning.

In providing education on a large scale, with thousands of students and hundreds of study centers, one of the difficulties is the distribution of educational content, where on Distance Education models, besides traditional texts, involves multimedia such as video files and learning interactive objects. To remedy this difficulty, in the face of lack of broadband internet in much of the state of Piauí, the project presented meets the need to associate the virtual learning environment to a service for the distribution of files on a large scale.

\subsection{The Operation of the Model}

Technically, the large-scale distribution for mobile is summarized as a multicast data transfer service (distribution to multiple points simultaneously) via satellite including 
management and scheduling system via web interface. The model allows videos and files to be transmitted via satellite multicast from a central point and can be stored on local concentrator units (a computer in every room at a study center). Therefore, the downloaded content could be accessed locally, after the transfer, without the consumption of satellite interconnection bandwidth. It should be available centralizing units installed in the computers themselves available on each study center with service already configured. Access to data stored in each location can be done by mobile devices available to students and teachers through local wireless connection (WI - FI) to be offered as part of the complementary structural implementation of the educational process platform.

For the system to work, each polo being structured with the following requirements:

- Support for 802.11n $2.4 \mathrm{GHz}$;

- Interface 1000Base-T RJ-45 connector for LAN connection;

- 128 MB RAM;

- 40 simultaneous accesses;

- Data Rate at 300 Mbps physical layer;

- Support for WPA/WPA2 Enterprise;

- Supports MIMO (multiple-input multiple output) 2x3;

- 3 to 5 dBiomni antennas;

- Desirable support 802.11s (mesh) in the firmware.

Figure 3 illustrates the use of the equipment described.

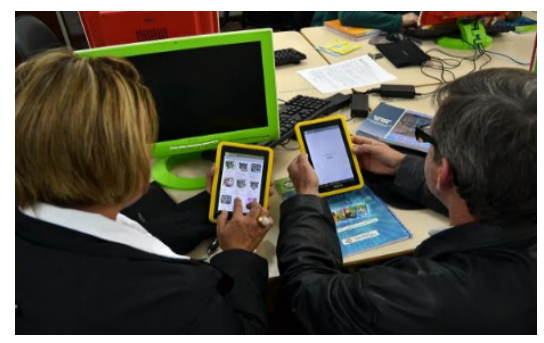

Fig. 3. Illustration of the use of tablet

The access points must be connected directly to the remote location gigabit switch with CAT6 UTP cables. Rooms far more than 100m from the switch, should use repeaters.

The project will be implemented in 2014, with students from Pronatec a Federal Government program, with technical courses in Administration, Agriculture, Nursing, Technology and Logistics, totaling 19,000 places. The budget for infrastructure of the study centers is estimated at $€ 923,720$, comprising equipment and technologies deployed at the study centers so that they have the ability to access and exchange information on large scale. 


\section{$5 \quad$ Expected Results}

It is hoped that the project will be one of the options to minimize the barriers to enlarge Distance Education in the country, which is the low level of digital inclusion of the population, especially the focus population of this study, in the rural area of the state of Piauí. At the heart of the 21st century many Brazilians still do not have Internet access, especially broadband. Even with current levels stating that the country is expanding the number of Internet users, the North and Northeast regions do not correspond to that statistic. The problem becomes even more severe in areas of difficult access, in the interior of the country, demanding governments to increase efforts to ensure universalization of the education, as seen throughout the article, and Distance Education as means to that end. The main benefit of the project is precisely to meet the educational deficiency, allowing that students without internet access can be integrated into programs of distance education.

The project intends to assist students of technical courses, minimizing the difficulties of this study model by the absence of necessary equipment such as internet, computer and digital knowledge. As a means of social inclusion, investment in education and improvement in learning processes, has led the state of Piauí to superior outcomes comparing to national average, such as; GDP growth, the results of evaluations of the quality of public education in the state, and its own generation of income and wealth in the State, being boosted by investment in qualified labor.

\section{Conclusion}

In the present article was presented and discussed a proposal to be implemented in 2014 in the distance education in the state of Piauí, in courses Pronatec of the Federal Government . The project aims to reduce the impacts of the digital exclusion present in some areas, by lack of infrastructure in rural areas and in all North and Northeast of Brazil. The lack of broadband internet is resolved with the large-scale distribution of equipment via mobile digital media, such as the tablet. The model is operated with Wifi access at the supported study centers, where students download the mobile devices with the content of the lessons, such as texts, videos and activities, studying retrospectively in an offline mode, solve the activities and unload it at the study centers, sending them for correction and receive new material. This action brought the possibility of securing access to the study material even without internet access, bringing digital social inclusion by enabling access to quality education and with proven efficacy in the country and in the world.

The expected results are still projections, since the project is in implementation phase, but is expected to improve learning, motivation from the student, reducing school dropout, adding value to the labour force available in the area, attending on a large scale, underserved regions with low cost. 


\section{References}

1. IBGE. Estado do Piauí. Disponível em,

http://www.ibge.gov.br/estadosat/perfil.php?sigla=pi

(Acesso em: 18 March 18, 2013)

2. FUNDAÇÃO CENTRO DE PESQUISAS ECONÔMICAS E SOCIAIS DO PIAUÍ, Avaliação das Contas Regionais do Piauí 2010 Disponível em (2010),

http://www. cepro.pi.gov.br/download/201212/

CEPRO13_f1e6e3e34a.pdf (Acesso em: March 20, 2013)

3. Buccelli, D.O., Espuny, H.G., Cavaleiro, J.C., de Oliveira Costa Neto, P.L., de Araujo Lopes, R., Romano, S.M.V.: Education mediated by technology: Strategy to spread high school learning in piauí state, brazil. In: Prabhu, V., Taisch, M., Kiritsis, D. (eds.) APMS 2013, Part II. IFIP AICT, vol. 415, pp. 334-341. Springer, Heidelberg (2013)

4. Yarmohammadian, M.H., Ahmadi, A., Sadrian, M., Fooladvand, M.: Evaluation of distance education programs based on the NADE-TDEC 2009-2010. Procedia - Social and Behavioral Sciences 28, 117-119 (2011)

5. Shin, D.H., Shin, Y.J., Choo, H., Beom, K.: Smartphones as smart pedagogical tools: Implications for smartphones as u-learning devices. Computers in Human Behavior 27(6), 2207-2214 (2011)

6. Aretio, L.G.: Educación a Distancia Hoy. Universidad Nacional de Educación a Distancia. Madrid (1994)

7. Moore, M., Kearsley, G.: Educação a Distância: uma visão integrada. São Paulo, Thomson Learning (2007)

8. Godoy, A.S.: Pesquisa Qualitativa: Tipos fundamentais. Pesquisa Qualitativa: Tipos fundamentais 35(3), 20-29 (1995) 